\title{
Rates and Determinants of Successful Vaginal Birth after a Previous Caesarean Section: A Prospective Cohort Study
}

\author{
George Uchenna Eleje ${ }^{1,2 *}$, Princeston C Okam², Emmanuel Ikechukwu Okaforcha ${ }^{2}$, Chinekwu \\ Sochukwu Anyaoku ${ }^{3}$ \\ ${ }^{I}$ Effective Care Research Unit, Department of Obstetrics and Gynecology, Faculty of Medicine, Nnamdi Azikiwe \\ University, Nnewi Campus, Nigeria \\ ${ }^{2}$ Department of Obstetrics and Gynecology, Nnamdi Azikiwe University Teaching Hospital, Nnewi, PMB 5025, \\ Nnewi, Nigeria \\ ${ }^{3}$ Department of Family Medicine, Nnamdi Azikiwe University Teaching Hospital, Nnewi, PMB 5025, Nnewi, \\ Nigeria
}

*Corresponding Author: Dr. George Uchenna Eleje, Effective Care Research Unit, Department of Obstetrics and Gynaecology, Nnamdi Azikiwe University, Awka (Nnewi Campus), P.M.B. 5001 Nnewi, Anambra State, Nigeria, Email: georgel21@yahoo.com; gu.eleje@unizik.edu.ng

\begin{abstract}
Objectives: To determine the rates and determinants of successful vaginal birth after a previous caesarean section (VBAC) among pregnant women with a previous caesarean section (CS).
\end{abstract}

Methods: This was a prospective cohort study of pregnant women, who attempted VBACs following one previous lower segment caesarean delivery in Nnamdi Azikiwe University Teaching Hospital (NAUTH), Nnewi, south-east Nigeria. Exclusion criteria were multiple gestations, more than one previous CS, or recurrent indications (clinical evidence of pelvic contraction, previous classical CS, and previous repair of vaginal fistula) for CS. Analysis was done with Epi info 2013 version 7.0 for Windows using descriptive and inferential statistics at $95 \%$ level of confidence.

Results: During the study period, 74 women were assessed for eligibility, but nine were excluded with 65 of the $74(87.8 \%)$ women being allowed trial of labour after one caesarean section (TOLAC). Of the 65 women that were allowed TOLAC, 22(33.8\%) had successful vaginal delivery, while 43 (66.2\%) had failed VBAC; giving a ratio of 1:3. Failed VBAC constituted $10.1 \%$ (43/424) of the total CS performed during the study period and the major indications were fetal distress and suspected macrosomia. Maternal age, booking status, socio-economic status, method of onset of labour, gestational age at delivery and birth weight had no significant association with success of VBAC $(p>0.05)$.

Only multiparity, history of successful vaginal delivery before and/or after first caesarean delivery had significant association with successful VBAC (P <0.05). The APGAR scores of the babies that had successful $V B A C$ were not significantly different from those of failed VBAC $(P>0.05)$. There were no maternal death, but there were 3 perinatal deaths, giving a perinatal mortality rate of 2.86/1000. None of the babies with successful VBAC suffered perinatal death.

Conclusion: Approximately one in every three women undergoing TOLAC had successful VBAC and significant determinants were multiparity, history a previous vaginal delivery before and/ or after the first CS. Proper and optimal antenatal evaluation of possible favourable factors for successful VBAC is needed.

Keywords: VBAC; multiparity; TOLAC; vaginal delivery

\section{INTRODUCTION}

Caesarean delivery has remained an important surgical intervention in contemporary obstetric practice [1-3]. Worldwide, primary and repeat caesarean delivery rates have reached their highest levels [4-6]. Even though, variation exists in the rates across countries; currently the

ARC Journal of Gynecology and Obstetrics rate ranges from $10 \%$ to $40 \%$ [6-8]. Due to increased risk of maternal complications on repeat caesarean section (CS) and safety of vaginal birth after caesarean section (VBAC), trial of labour for selected group of patients with a previous lower segment transverse scar has become a favorite strategy [7]. 
In 1988, American College of ObstetricianGynaecologist (ACOG) recommended that, in the absence of a contraindication, a woman with one previous low-transverse caesarean delivery be counseled to attempt labour in a subsequent pregnancy $[7,9]$. ACOG further suggests that a woman with a twin pregnancy or a woman who requires induction of labour may also be considered candidates for vaginal birth after caesarean section (VBAC) with appropriate counseling [9].

In general, 60 to $80 \%$ success rate of $\mathrm{VBAC}$ has been reported by many authors if the primary caesarean was done for nonrecurring indications [3]. Some of the nonrecurring indications for CS include poor progress of labour, fetal distress, cord prolapse, placenta previa, transverse lie, breech presentation, pregnancy induced hypertension and multiple pregnancy $[9,10]$.

Nevertheless, there is considerable variation in the proportion of women who are offered and attempted VBAC across centres. British figures indicate that among women with a prior caesarean section, 33\% will successfully achieve vaginal birth in the subsequent pregnancy and institutional variations ranged from $6 \%$ to $64 \%$ [11, 12]. The leading indications for the repeat CS were: failure to progress, fetal distress and scar tenderness $[13,14]$.

The intriguing questions are how to reliably predict successful VBAC, and how to determine and quantify the magnitude of the risk of failure that is acceptable to women. Many studies have addressed methods for identifying women at low and high risk of failure of an attempted VBAC but none of them has resulted in a validated result [1-3]. Even those factors found to be associated with successful VBAC vary from centre to centre. Currently, therefore, there is no single validated tool which holds true for all to predict successful vaginal birth among women with a prior caesarean delivery.

In a previous retrospective study in NAUTH, Nnewi, in Nigeria, Ikechebelu et al [15] reported a successful vaginal delivery of $46.7 \%$ among women that underwent trial of labour after one caesarean section (TOLAC) between 2001 and 2005 while Obiechina et al [16] reported successful vaginal delivery of $59.5 \%$ among women that underwent TOLAC between 2002 and 2006. As at the time of their study, the average CS rate in NAUTH was $18.4 \%$ but since then the CS rate has been rising such that Eleje et al [17] in 2010 reported a CS rate of
$26.9 \%$ with one previous CS scar being the commonest indication. Therefore, while it does appear that the rate of successful VBAC is increasing over the years in Nnewi, Nigeria, there is unexpected corresponding increase in CS rate with failed VBAC being the most common culprit. Additionally, CS rate may be increasing in Nigeria because of the flourishing private hospitals in major towns and possibly increasing cases of litigation. Even though teaching hospitals offer trial of labour for mothers with one scar, there is no prospective study done which shows the rate of VBAC acceptance and success in Nigerian hospitals.

Therefore, the objective of the present study was to prospectively identify maternal demographic, past and present obstetric determinants of successful VBAC in teaching hospital in Nnewi, Nigeria. This will be of great help for obstetricians in the joint obstetrician-patient decision while offering TOLAC in Nigeria.

\section{SubJeCtS AND Method}

\subsection{Study Area}

This study was conducted in Nnamdi Azikiwe University Teaching Hospital (NAUTH), Nnewi, south-east Nigeria. This teaching hospital provides a 24 hour specialty care. Most of the deliveries and evaluations are made by nurse midwives, resident doctors with a consultant supervision. NAUTH offers trial of labour (TOL) with informed consent from the women if the following conditions are fulfilled: the mother has one previous lower uterine segment scar, nonrecurring previous indications, singleton pregnancy, cephalic presentation, estimated fetal weight less than or equal to 4.0 $\mathrm{kg}$, and no current indication for CS.

\subsection{Study Period}

This study included mothers accepting a TOL and delivering in the time period of data collection from July 1st 2013 to June 30th 2014.

\subsection{Study Design}

This study was a prospective cohort study.

\subsection{Study Population}

This included all consenting pregnant women seen in the labour ward during the period of the study and who met the inclusion criteria.

\subsection{Inclusion Criteria}

The inclusion criteria included consenting pregnant women with one previous lower 
uterine segment CS scar who came for induction of labour or with spontaneous labour or leakage of liquor, with no contraindication for VBAC and allowed to undergo trial of labour by the managing obstetrician and delivered through the vaginal route or emergency $\mathrm{CS}$ due to failed VBAC.

\subsection{Exclusion Criteria}

Those women who had multiple gestations and women with more than one previous CS were excluded. Women who had CS for a reason that would typically lead to another caesarean delivery in subsequent pregnancies (recurrent indications) were also excluded. Such recurrent indications included women with clinical evidence of pelvic contraction, previous classical CS, and previous repair of vaginal fistula.

\subsection{Data Collection Method}

Factors associated with successful VBAC among mothers with one previous caesarean section were identified. Women were allowed for VBAC according to the hospitals protocol such as women having spontaneous/ induced onset of labour and delivered by vaginal route. Ethical clearance was obtained from NAUTH Ethics committee. Women for the study were interviewed and data collected immediately after the patients arrived at labour ward or prenatal ward for delivery. All women included in the study were followed through delivery and for at least 48 hours after delivery. Information was sought directly from the women and recorded in a structured proforma which included maternal socio demographic, past and present obstetric experience, mode of delivery and birth outcomes variables.

\subsection{Variables}

Socio demographic variables included: maternal age, marital status, parity, gestational age and booking status. The past obstetric variables included: gestational age at labour or delivery, history of prior successful VBAC and spontaneous vaginal delivery (SVD).

The current obstetric and fetal factors included: status of the baby at admission of the women in the labour ward, birth weight and outcome of the baby. A failed TOLAC was defined as a repeat caesarean delivery after spontaneous onset of labour or induction or stimulation of labor, while a successful TOLAC was defined as a vaginal birth after CS. Induction of labour is defined as "the initiation of uterine contractions before the spontaneous onset of labour by medical and/or surgical means for the purpose of delivery," which includes births induced by oxytocin. For the cases of induction of labour, cervical ripening was done by intra cervical Foley catheter.

\subsection{Data and Statistical Analysis}

Data were entered after checking completeness, cleaning and coding into EXCEL Spread sheet and analysed using computer EPI-Info 2013 version 7 (v 7; Epi Info, Centers for Disease Control and Prevention, Atlanta, GA). Proportions were compared by Students' t-test, Chi-square or Fisher exact test where appropriate and the statistical significance of $P$-value was $P<0.05$.

\section{Results}

During the study period, a total delivery of 1050 occurred. Of the 1050 deliveries, 424(40.4\%) women had CS from various indications while $626(59.6 \%)$ women had vaginal delivery, giving a CS rate of $40.4 \%$. Also during the study period, 74 women were recruited. Nine of the recruited women who had elective CS were excluded from the analysis because the women did not undergo TOLAC due to recurring indications, thereby yielding a final achieved sample of 65 . This means that 65 of the 74 $(87.8 \%)$ women were allowed TOLAC.

Table1. Socio-Demographic Characteristics of the Women

\begin{tabular}{|c|c|c|}
\hline Variables & $\begin{array}{c}\text { Frequency } \\
(\mathbf{N}=65)\end{array}$ & Percentage \\
\hline \multicolumn{3}{|l|}{ Age } \\
\hline $20-24$ & 9 & 13.8 \\
\hline $25-29$ & 25 & 38.5 \\
\hline $30-34$ & 23 & 35.4 \\
\hline $35-39$ & 7 & 10.8 \\
\hline $40-44$ & 1 & 1.5 \\
\hline \multicolumn{3}{|c|}{ Booking Status } \\
\hline Booked & 47 & 72.3 \\
\hline Un-booked & 18 & 27.7 \\
\hline \multicolumn{3}{|l|}{ Parity } \\
\hline 1 & 31 & 47.7 \\
\hline $2-4$ & 32 & 49.2 \\
\hline$\geq 5$ & 2 & 3.1 \\
\hline \multicolumn{3}{|c|}{ Educational level } \\
\hline Primary & 1 & 1.5 \\
\hline Secondary & 43 & 66.2 \\
\hline Tertiary & 21 & 32.3 \\
\hline \multicolumn{3}{|l|}{ Social Class } \\
\hline $\mathrm{I}$ & 19 & 29.2 \\
\hline II & 40 & 61.6 \\
\hline III & 6 & 9.2 \\
\hline
\end{tabular}


Rates and Determinants of Successful Vaginal Birth after a Previous Caesarean Section: A Prospective Cohort Study

The mean age of the respondents was $30.5 \pm 5.1$ years (range $=20-44$ years). All the women were married and majority, 43 (66.2\%) had secondary level of education. The socio-demographic characteristic of the respondents' is shown in table 1 .

Of the 65 women, 22(33.8\%) had successful vaginal delivery after TOLAC while 43 (66.2\%) women had failed VBAC and subsequently had repeat $C S$; given a ratio of $1: 3$. Therefore, failed VBAC constituted $10.1 \%$ (43/424) of the total CS performed during the study period.

Of the 65 women, 59 (90.8\%) women had spontaneous onset of labour while six $(9.2 \%)$ women had induced labour. Of the six women that had induction of labour, $5(83.3 \%)$ had Foley catheter inserted intracervically for cervical ripening while one $(16.7 \%)$ unbooked and referred case had misoprostol used for cervical ripening. Only one woman (unbooked) received misoprostol for cervical ripening had uterine rupture.

The mean age of the women with successful VBAC was 31.1 \pm 4.1 years (range $=22-44$ years) while the mean age of those who had failed VBAC was 30.0 \pm 4.9 years (range $=20-44$ years). The observed difference was not statistically significant $(t=0.70 ; p=0.109)$. Similarly, other factors such as booking status, socio-economic status, method of onset of labour, gestational age at delivery and birth weight had no significant association with success of VBAC ( $p$ $>0.05$ ). The association between the successful VBAC and women's socio-demographic, maternal and fetal characteristics is shown in table 2 .

Only multiparity, history of successful vaginal delivery before first CS and history of successful vaginal birth after the first CS had significant association with successful VBAC (P $<0.05)$.

There were three cases $(1.5 \%)$ of uterine rupture (one booked and two unbooked). Two were admitted as cases of uterine rupture with intrauterine fetal death following a trial of labour at home. One patient ruptured her uterus while on the labour ward and her baby was, however, alive. One of the cases (unbooked) had cervical ripening with misoprostol admission at the study hospital.
Table2. Association between Successful VBAC and Women and Fetal' Characteristics

\begin{tabular}{|c|c|c|c|}
\hline Variables/subgroup & $\begin{array}{c}\text { Successful } \\
\text { VBAC } \\
\text { Group } \\
(\mathbf{N}=22)\end{array}$ & $\begin{array}{l}\text { Failed } \\
\text { VBAC } \\
\text { group } \\
(\mathrm{N}=43)\end{array}$ & P-value \\
\hline Mean Age & $\begin{array}{l}31.1 \pm 4.12 \\
\text { years }\end{array}$ & $\begin{array}{l}30.0 \pm 4.85 \\
\text { years }\end{array}$ & 0.534 \\
\hline \multicolumn{4}{|l|}{ Booking Status } \\
\hline Booked & 19 & 28 & \multirow[t]{2}{*}{0.061} \\
\hline Unbooked & 3 & 15 & \\
\hline \multicolumn{4}{|l|}{ Parity } \\
\hline Primiparous & 5 & 21 & \multirow[t]{2}{*}{$* 0.037$} \\
\hline Multiparous & 17 & 22 & \\
\hline \multicolumn{4}{|l|}{ Socio-economic Class } \\
\hline High & 20 & 39 & \multirow[t]{2}{*}{0.670} \\
\hline Low & 2 & 4 & \\
\hline \multicolumn{4}{|c|}{ Method of Onset of labour } \\
\hline Spontaneous & 20 & 39 & \multirow[t]{2}{*}{0.670} \\
\hline Induced & 2 & 4 & \\
\hline \multicolumn{4}{|c|}{$\begin{array}{l}\text { Previous Successful Vaginal Delivery before the } \\
\text { First CS }\end{array}$} \\
\hline Yes & 13 & 4 & \multirow[t]{2}{*}{$*<0.001$} \\
\hline No & 9 & 3 & \\
\hline \multicolumn{4}{|c|}{ Previous Successful VBAC } \\
\hline Yes & 13 & 3 & \multirow[t]{2}{*}{$*<0.001$} \\
\hline No & 9 & 39 & \\
\hline \multicolumn{4}{|c|}{ Birth Weight of the baby (Kg) } \\
\hline$\leq 3.5$ & 18 & 28 & \multirow[t]{2}{*}{0.132} \\
\hline$>3.5$ & 4 & 15 & \\
\hline \multicolumn{4}{|c|}{ APGAR Score in $1 \mathrm{~min}$} \\
\hline$\leq 6$ & 1 & 3 & \multirow[t]{2}{*}{0.583} \\
\hline$>6$ & 21 & 40 & \\
\hline \multicolumn{4}{|l|}{ Uterine Rupture } \\
\hline Yes & 0 & 3 & \multirow[t]{2}{*}{0.283} \\
\hline No & 22 & 40 & \\
\hline \multicolumn{4}{|c|}{ Gestational age at Delivery } \\
\hline$\geq 40$ weeks & 10 & 21 & \multirow[t]{2}{*}{0.502} \\
\hline$<40$ weeks & 12 & 22 & \\
\hline
\end{tabular}

Table3. Indications for caesarean section in women that had failed VBAC

\begin{tabular}{|l|l|l|}
\hline Indications & Frequency & Percentage \\
\hline Fetal distress & 11 & 22.9 \\
\hline $\begin{array}{l}\text { Suspected } \\
\text { macrosomia }\end{array}$ & 11 & 22.9 \\
\hline Malpresentation & 7 & 14.5 \\
\hline $\begin{array}{l}\text { Cephalopelvic } \\
\text { disproportion }\end{array}$ & 5 & 10.4 \\
\hline Borderline pelvis & 4 & 8.3 \\
\hline $\begin{array}{l}\text { Imminent uterine } \\
\text { rupture }\end{array}$ & 3 & 6.3 \\
\hline $\begin{array}{l}\text { Obstructed } \\
\text { labour }\end{array}$ & 3 & 6.3 \\
\hline $\begin{array}{l}\text { Severe } \\
\text { oligohydramnios }\end{array}$ & 2 & 4.2 \\
\hline Cervical stasis & 2 & 4.2 \\
\hline Total & 48 & 100.0 \\
\hline
\end{tabular}

*Five women had more than one indication. 
No maternal death was seen in this study. However, there were three perinatal deaths, two of which were intrauterine fetal deaths before admission. All the three perinatal deaths occurred among patients that had failed VBAC. The clinical cause of death was uterine rupture, giving perinatal mortality rate of $2.86 / 1000$. None of the patients that had successful VBAC suffered perinatal death. The APGAR scores of the babies delivered by successful VBAC were not significantly different when compared to babies delivered by emergency CS due to failed VBAC.

\section{DISCUSSION}

The route of delivery after one previous lower segment CS represents one of the most significant and challenging debates in contemporary obstetric practice [18]. This study has shown that the CS rate in the institution during the study period was $40.4 \%$. CS from failure of successful vaginal birth after one previous CS constituted $10.1 \%$ of all cases of CS and $4.1 \%$ of all deliveries. A high caesarean section rate of up to $40.4 \%$ has also been documented in other studies in Nigeria $[4,5$, 18]. This higher rate of caesarean delivery could be explained by the fact that our health care institution is a referral hospital, where many high-risk pregnancies are seen and managed. This is because $87.8 \%$ of the women with previous caesarean delivery were allowed a trial of vaginal delivery. Similar high incidences have also been reported by other authors $[4,18$ 20].

The successful vaginal delivery rate of $33.8 \%$ was lower than the range of $60-80 \%$ reported in the literature $[4,6,20,21]$. It was also lower than previous study by Ikechebelu et al [15] $(46.7 \%)$ and Obiechina et al [16] (59.5\%) in Nnewi, Nigeria, the location of the hospital of study. However, a similar reduced successful vaginal delivery rate has also been reported by other published reports [21-24]. A dramatic decrease in the rate of VBAC has also been observed in the United States during recent years from $28.3 \%$ in 1996 to $9.2 \%$ in 2004 [25].The reduced successful vaginal delivery rate in this study could be a reflection of the increasing trend in the incidence of CS including increasing rate of litigation, the high number of cases of patients who had emergency CS for fetal distress, suspected macrosomia and malpresentations. CS rate may have increased due to use of continuous electronic fetal monitoring, which was not frequently used a decade earlier. Thus, this reason may explain why the commonest indication for caesarean section was fetal distress. The lower rate was due partly to the fact that trial of vaginal delivery was offered to patients who met the selection criteria, and partly because patients with some indications including fetal macrosomia, malpresentations and placenta praevia who should have elective surgery presented as an emergency in the labour ward, when they could not deliver at home. Patients should therefore be selected on individual merit for trial of vaginal birth.

As seen in this study, successful vaginal delivery has been found to be significantly influenced by prior history of previous vaginal delivery before and after caesarean delivery as reported in various published study $[18,19]$. It is surprising that there is no significant association between the outcome of trial of vaginal birth after CS and the booking status, socio-economic status, method of onset of labour, gestational age at delivery and birth weight of the babies ( $p$ $>0.05$ ). These findings contrasts with previous reports in Nigeria by Ilesanmi et al [26], Ola et al [19] and Iyoke et al [4] where spontaneous onset of labour, birth weight of less than $4 \mathrm{~kg}$, and gestational age of less than 40 weeks predicts successful trial of VBAC. This lack of association could be because approximately $30 \%$ of women were unbooked and were admitted as emergency after having tried VBAC in a peripheral hospital where the women selection would have been suboptimal. Also their labour would have been either unsupervised or supervised by unskilled and untrained personnel who only ask them out when the situation is bad.

Thus, some of these women would have undergone trial of VBAC even when they ought not to have attempted it in the first place. In our society, there is strong aversion for CS and usually there is general erroneous belief that there is a likelihood of repeat CS if they labour in a hospital with operative facility. Much to our chagrin, some women in this study who had their antenatal care in our facility and received proper counseling absconded to places without maternity services at the mention of possible CS only to present again in the study hospital when things were not progressing as they expected.

Previous published reports in the literature [18, 25 ] have suggested a significant risk of uterine 
rupture with poor outcome for both the woman and her infant following vaginal delivery. Unfortunately, up to date, there are no reliable ways to predict the trial of labour after one CS that will result in emergency CS or successful vaginal birth $[5,9]$.

In this study there were three $(1.5 \%)$ cases of uterine rupture (one booked and two unbooked). Two were admitted as cases of uterine rupture with intrauterine fetal death following a trial of labour at home. One patient ruptured her uterus while in the labour ward and her baby was, however, alive. One of the cases (unbooked) had cervical ripening with misoprostol admission at the study hospital. There was salvage for baby whose mother ruptured her uterus in the labour ward compared with mothers who ruptured before admission, because they were unbooked and chose to labour at home. Although, three patients that had induction of labour received intracervical Foley catheter for cervical ripening, ACOG and RCOG agree that induction of labour for maternal or fetal indications is an option for women undergoing TOLAC. There is further agreement that when informing a woman about induction and/or augmentation, clear information should be provided on all potential risks and benefits, especially the potential increased risk of uterine rupture and the potential decreased possibility of achieving VBAC.

Major complications have also been reported following the use of misoprostol [5, 27, 28]. Even though this study reported one uterine rupture following cervical ripening using misoprostol, uterine ruptures were also noted in women who were not augmented, stimulated or induced.

Although previous studies in Nigeria and its sub region had reported maternal mortality in women undergoing TOLAC, the case fatality rate shown from our cohort was 0\%. This finding was similar to report by Okpere et al [29] in Benin City, Nigeria. However, the perinatal mortality rate was $2.86 / 1000$. As shown in this study, results of studies on the impact of mode of delivery on low APGAR scores are discordant and do not justify any conclusion. Still, most studies have not found that admission to the intensive care unit differs according to mode of delivery [30, 31]. The APGAR score of babies delivered by emergency caesarean section was not statistically different from that had successful vaginal delivery.
Similarly, Okpere et al. [29] in his earlier report revealed higher perinatal deaths. A number of factors may be responsible to this improved trend. Continuous electronic fetal monitoring and intrapartum care for the duration of planned VBAC to enable prompt identification and management of uterine scar rupture as strongly recommended by ACOG is being practiced in our hospital.

This study has a number of limitations. It is important to acknowledge that this study does not answer the question regarding optimal approach to delivery for women with prior caesarean who must be delivered for maternal or fetal indications. This study has relatively limited sample size and did not compare women undergoing TOLAC with those undergoing planned repeat caesarean section. Such a comparison is needed for further study. We also recognise that categorising the indication for the previous caesarean section into 'recurrent and non-recurrent indications' may be limited by the fact that the obstetrician may not have managed the previous delivery and the previous labour record may not be readily volunteered by the women studied. This is because; recurrent indication for the previous caesarean section is known to be associated with a comparatively lower rate of successful vaginal delivery.

\section{CONCLUSiON}

This study has shown that approximately one third of the women with one previous caesarean section had successful vaginal birth after TOLAC. Significant determinants of successful VBAC in the cohort of women studied were multiparity, history a previous vaginal delivery before and after the first caesarean section VBAC was not risk free for the fetus. It is recommended that consultation to these women should include evaluation for the likelihood of successful TOLAC and the risk of uterine rupture based on the many other previously reported risk factors in order to stratify the risk associated with TOLAC and to allow optimal patient selection.

\section{REFERENCES}

[1] Denham SH, Humphrey T, deLabrusse C, Dougall N. Mode of birth after caesarean section: individual prediction scores using Scottish population data.BMC Pregnancy Childbirth. 2019 Feb 28;19(1):84. doi: 10.1186/s12884-019-2226-6.

[2] LyckestamThelin I, Lundgren I, Nilsson C. To challenge oneself as a childbearing woman-the 
lived experience of vaginal birth after caesarean section in Sweden.Int J Qual Stud Health Wellbeing. 2019 Dec;14(1):1605784. doi: 10.1080/ 17482631.2019.1605784.

[3] Ryan GA, Nicholson SM, Morrison JJ. Vaginal birth after caesarean section: Current status and where to from here?Eur J Obstet Gynecol Reprod Biol. 2018 May;224:52-57. doi: 10.1016/j.ejogrb.2018.02.011. Epub 2018 Mar 7.

[4] Iyoke CA, Ugwu GO, Ezugwu FO, Lawani OL, Onah HE. Risks associated with subsequent pregnancy after one caesarean section: A prospective cohort study in a Nigerian obstetric population. Niger J Clin Pract. 2014 Jul-Aug; 17(4):442-8. doi: 10.4103/1119-3077.134035.

[5] Knight H.E, Gurol-Urganci I, van der Meulen JH, Mahmood TA, Richmond DH, Dougall A, Cromwell DA. Vaginal birth after caesarean section: a cohort study investigating factors associated with its uptake and success. BJOG 2013; 10.1111/1471-0528.12508.

[6] Ugwu GO, Iyoke CA, Onah HE, Egwuatu VE, Ezugwu FO. Maternal and perinatal outcomes of delivery after a previous Cesarean section in Enugu, South east Nigeria: a prospective observational study. Int $\mathrm{J}$ Womens Health. 2014 Mar 13; 6:301-5.

[7] American College of Obstetricians and Gynecologists (ACOG): ACOG Practice Bulletin: vaginal birth after previous cesarean delivery: Clinical management guidelines. Int J GynecolObstet 2004, 54:197-204.

[8] Ugwumadu A. Does the maxim "once a caesarean, always a caesarean" still hold true? PLoS Med 2005, 2(9):e3053.

[9] American College of Obstetricians and Gynecologists. ACOG Practice bulletin no. 115: Vaginal birth after previous cesarean delivery. ObstetGynecol 2010; 116:450.

[10] Mozurkewich EL, Hutton EK. Elective repeat cesarean delivery versus trial of labor: a metaanalysis of the literature from 1989 to 1999. Am J Obstet Gynecol 2000; 183: 1187.

[11] Boulvain M, Fraser WD, Brisson-Carroll G, Faron G, Wollast E. Trial of labor after caesarean section in sub-Saharan Africa: a meta-analysis. BJOG 1997, 104:1385-1390.

[12] Jodie MD, Caroline AC, Janet EH, Ross RH, Jeffery SR. Vaginal birth after caesarean. BMC Childbirth and Pregnancy 2007, 7:17.

[13] Taj G, Sohail N, Cheema SZ, Zahid N, Rizwan S: Review of Study of Vaginal Birth After Caesarean Section (VBAC). Annals 2008, 14(1):13-16.

[14] Chen HY, Chauhan SP, Grobman WA, Ananth CV, Vintzileos AM, Abuhamad AZ. Association of labor induction or stimulation with infant mortality in women with failed versus successful trial of labor after prior caesarean. J Matern Fetal Neonatal Med, 2013; 26(12): 1162-1165.

[15] Ikechebelu JI, Mbamara SU, Afuba AN. Vaginal birth after one caesarean section: A review of the practice at Nnewi, southeast Nigeria. Journal of Medicine and Medical Science, 2010; 1(7): 309-313.

[16] Obiechina NJA, Ezeama CO, Ezenri U, Ugboaja JO. Outcome of Pregnancy following a Previous Lower Segment Caesarean Section: A Five Year Study at The NnamdiAzikiwe University Teaching Hospital Nnewi (20022006). Tropical Journal of Medical Research, 200711 (1): 25-28.

[17] Eleje GU, Udigwe GO, Akabuike JC, Eke AC, Eke NO, Umeobika JC. The rate of Caesarean section in Nnewi, Nigeria: A 10-year Review. Afrimedic J, 2010; 1:11-4.

[18] Aisien AO, Oronsaye AU. Vaginal birth after one previous caesarean section in a tertiary institution in Nigeria. J ObstetGynaecol. 2004 Nov; 24(8):886-90.

[19] Ola ER, Imosemi OD, Abudu OO. Vaginal birth after one previous Caesarean section-evaluation of predictive factors. Afr J Med Med Sci. 2001 Mar-Jun; 30(1-2):61-6.

[20] Thistle PJ, Chamberlain JA. Vaginal birth after caesarean section in a rural African setting. International J. Gynecol Obstet, 2002; 77: 31 32.

[21] Adjahoto EO, Ekouevi DK, Hodonou KA. Factors predicting outcome of trial of labour after prior caesarean section in developing countries. Journal de Gynecologie, Obstetriqueet Biologie de la Reproduction, 2001; 30: 174 - 179 .

[22] Obara H, Minakami H, Koike T, Takamizawa S, Matsubara S, Sato I. Vaginal birth after caesarean delivery: results of 310 pregnancies. J Obstet Gynaecol Res, 1998; 24: 129 - 134.

[23] Appleton B, Targett C, Rasmussen M, Readman E, Sale F, Permezel M. Vaginal birth after caesarean section: an Australian multicentre study. VBAC Study Group. Aust New Zealand J Obstet Gynaecol, 2000; 40: 87 91.

[24] Menacker F, Declercq E, Macdorman MF. Cesarean delivery: background, trends, and epidemiology. SeminPerinatol 2006;30: 235-41.

[25] McMahon MJ, Luther ER, Bowes WA. Jr, Olshan AF. Comparison of a trial of labour with an elective second caesarean section. New England Journal of Medicine, 1996; 335, 689 695.

[26] Ilesanmi AO, Odukogbe A, Olaleye DO. Vaginal delivery after one caesarean section in 
Nigerian women. J Obstet Gynaecol. 1997 Mar; 17(2):139-42.

[27] Ezechi OC, Kalu EE, Njokanma FO, Ndububa CA, Nwokoro CA, Okeke GCE. Trial of labour after previous caesarean delivery: a private hospital experience. Annals of African Medicine. 2005;4(3): 113-117.

[28] Lydon-Rochelle M, Holt VL, Easterling TR, Martin DP. Risk of uterine rupture during labour among women with a prior caesarean delivery. New England Journal of Medicine, 2001; 345, 3-8.

[29] Okpere EE, Orosanye AV, Imoedmher DAG. Pregnancy and Delivery after caesarean section: a review of 494 cases. Trop J Obstet Gynecol. 1981; 3:45-48.

[30] Lopez E, Patkai J, El Ayoubi M, Jarreau PH. Benefits and harms to the newborn of maternal attempt at trial of labour after prior caesarean versus elective repeat caesarean delivery. J Gynecol Obstet Biol Reprod. 2012; 41:727734.

[31] Haumonté JB, Raylet M, Sabiani L, et al. Predictive factors for vaginal birth after caesarean section. J Gynecol Obstet Biol Reprod. 2012; 41:735-752

Citation: George Uchenna Eleje, Princeston C Okam, Emmanuel Ikechukwu Okaforcha, Chinekwu Sochukwu Anyaoku. Rates and Determinants of Successful Vaginal Birth after a Previous Caesarean Section: A Prospective Cohort Study. ARC Journal of Gynecology and Obstetrics. 2019; 4(2):1-8. DOI:dx.doi.org/10.20431/2456-0561.0402001.

Copyright: (C) 2019 Authors. This is an open-access article distributed under the terms of the Creative Commons Attribution License, which permits unrestricted use, distribution, and reproduction in any medium, provided the original author and source are credited. 